\title{
ECLESIÁSTICOS \\ EN LA DIPLOMACIA CASTELLANA EN EL SIGLO XV ${ }^{1}$
}

\author{
CLERGYMEN IN DIPLOMACY \\ IN THE FIFTEENTH CENTURY CASTILE
}

\author{
ÓSCAR VILLARROEL GONZÁLEZ \\ Universidad Complutense de Madrid
}

\begin{abstract}
Resumen: Los eclesiásticos participaron de forma activa y recurrente en la diplomacia durante lo siglos medievales. Su dominio del latín, entre otras cosas, fue clave en el hecho de que fuesen personajes idóneos para colaborar con la Monarquía en tales cometidos. En el presente estudio se analiza la figura de los eclesiásticos que desempeñaron labores diplomáticas en Castilla en el siglo XV. Se analiza quiénes, cómo y por qué fueron elegidos para esas tareas, atendiendo a su formación y su jerarquía eclesiástica.
\end{abstract}

Palabras clave: Monarquía; Diplomacia; Reino de Castilla; Eclesiásticos; Siglo XV.

\begin{abstract}
The clergymen were, along the Middle Ages, usually members of the diplomatic services of the Monarchy. The fact of know the Latin was, among other things, the key that were suitable to work for the Monarchy in this kind of tasks. This study analyzes the figure of the clergymen who played in diplomatic works in the fifteenth century. It analyzes who, why and how they were chosen for these tasks, attending on his studies and hierarchy.
\end{abstract}

Keywords: Monarchy; Diplomacy; Kingdom of Castile; Clergymen; 15th century.

\section{SUMARIO}

1. Introducción.- 2. Ensayo de una nómina de los embajadores.- 3. Los destinos y las tareas encomendadas: 3.1. Francia. 3.2. Inglaterra. 3.3. El papado y los concilios. 3.4. Portugal. 3.5. Aragón. 3.6. Navarra. 3.7. El Imperio y otros ámbitos.- 4. Formación y extracción: análisis cuantitativo.- 5 . Conclusiones

\section{INTRODUCCIÓN}

Hoy día no tiene nada de extraordinario el admitir que a lo largo del periodo medieval se desarrolló la actividad diplomática, de forma más extensa en unos periodos que en otros, y con mayor incidencia en algunos territorios.

${ }^{1}$ Este trabajo forma parte del Proyecto de investigación financiado por el Ministerio de Ciencia e Innovación n $\mathrm{n}^{6}$ HAR2010-16762, titulado "Prácticas de Consenso y de pacto e 
Actividad diplomática que no hemos de subsumir en las relaciones internacionales, lo que ha llevado a algún autor a dudar que pudiesen existir en época medieval $^{2}$. No cabe duda que hubo relaciones diplomáticas en el periodo medieval. Además, hoy día tampoco es nada novedoso indicar que en este periodo, y más en concreto del bajomedieval, los eclesiásticos desarrollaron un amplio papel como embajadores y delegados de tipo diplomático. Es lugar común el indicar que desarrollaban un papel muy importante gracias a sus conocimientos del latín, lengua que actuó durante todo el periodo como la auténtica lengua franca. También lo es el afirmar el que el hecho de que el juramento tuviese notable peso como forma de compromiso diplomático tuvo también relevancia en su elección, al tratarse de un compromiso netamente religioso ${ }^{3}$.

De este modo, decir que en la diplomacia castellana del siglo $\mathrm{XV}$ participaron eclesiásticos no es nada novedoso. Pero, ¿quiénes desarrollaron esa diplomacia? ¿Existe alguna línea organizativa en el tipo de personal a su servicio en esa cuestión que tuvo la monarquía castellana? ¿Hay diferencias entre un reinado y otro? Dada la extensa conflictividad política interna del reino durante ese siglo, ¿influyó en la elección de los delegados regios? Dado ese problema, los conflictos constantes, es necesario hacer una reducción del espacio temporal. En concreto, se analizará desde el advenimiento de Enrique III hasta la muerte de Enrique IV. Queda fuera, pues, el reinado de los Reyes Católicos, tan decisivo y tan relevante para la modernidad, puesto que él sólo se merece un análisis exclusivo.

A la hora de atender a la actividad diplomática de los eclesiásticos en el siglo XV castellano debemos atender a diversos aspectos. Hay una serie de cuestiones básicas: qué labor diplomática realizan, quiénes son, a dónde se dirigen, qué formación tenían. Para ello haremos un somero repaso a las diferentes embajadas, aunque sea una mera enumeración, de los enviados. También a los distintos ámbitos a los que se prestó atención. Habrá que atender también a los propios embajadores: su formación, su grado dentro de la jerarquía eclesiástica, y su origen familiar (en caso de que sea relevante). Todo esto nos permitirá apreciar la existencia, o inexistencia, de una línea común o evolución, a lo largo de todo el periodo.

\section{ENSAYO DE UNA NÓMINA DE LOS EMBAJADORES ECLESIÁSTICOS}

Es difícil realizar una nómina exacta de los enviados diplomáticos que los reyes de Castilla enviaron desde finales del siglo XIV hasta el final del

\footnotetext{
${ }^{2} \mathrm{Al}$ respecto, véanse las apreciaciones que hice en la introducción de mi El rey y el papa. Política y diplomacia en los albores del Renacimiento (Castilla en el siglo XV), Madrid, 2009, pp. 17-22.

${ }^{3}$ Véase por ejemplo, José Manuel NIETO SORIA, Iglesia y poder real en Castilla: el episcopado 1250-1350, Madrid, 1998, pp. 48-58.
} 
reinado de Enrique IV. La dispersión de las fuentes, la no conservación de alguna de ellas, y lo fragmentario de las noticias (a la par de la falta de una abundante historiografía al respecto), hace que la tarea se plantee difícil. Sin embargo, es posible presentar una nómina que tienda a la exhaustividad, aunque no podamos darla por cerrada.

Entre el inicio del reinado de Enrique III y la muerte de Enrique IV se documenta la presencia de un total de noventa eclesiásticos que, en algún momento, desarrollaron alguna actividad diplomática al servicio de la Monarquía castellana. La lista es extensa, pero para un mejor conocimiento creo que es preferible presentarla:

-Alfonso de Alcocer, al papa Benedicto XIII en Aviñón en $1405^{4}$, y en Francia ese mismo año ${ }^{5}$.

-Alfonso de Argüello, enviado a Benedicto XIII en $1397^{6}$, de nuevo en $1402^{7}$ permaneciendo hasta $1405^{8}$; y en 1415 a Aragón con motivo de la boda de la infanta María9. $1463^{10}$

-Alfonso Carrillo, negociaciones con Francia en Fuenterrabía en

-Alfonso de Cartagena, en Portugal entre 1421 y $1423^{11}$, en $1424^{12}$, y en $1425^{13}$, tal vez hasta $1426^{14}$, y por último en $1427^{15}$, en el Concilio de Basilea entre 1434 y 1438 , en el Imperio en 1438 y $1439^{16}$, y ante la reina navarra en $1440^{17}$.

${ }^{4}$ M.A. OCHOA BRUN, Historia de la diplomacia española, I, Madrid, 1991, p. 227.

${ }^{5}$ L. SuÁrez FernándeZ, Castilla, el Cisma y la crisis conciliar (1378-1440), Madrid, 1960, p. 57.

${ }^{6}$ A. LÓPEZ, Fray Fernando de Illescas, confesor de los reyes de Castilla Juan I y Enrique III, "Archivo Ibero-Americano", 88 (1928), pp. 241-252, p. 248.

${ }^{7}$ L. SUÁREZ FERNÁNDEZ, Castilla, p. 46.

${ }^{8}$ Archivo General de Simancas (en adelante AGS), Estado-Castilla, leg. 1-1, f- 53; publicado en Ibídem, pp. 257-258.

${ }^{9}$ L. GalínDEZ DE CARvajal, Crónica Crónica del serenísimo príncipe don Juan II de Castilla, en el tomo II de las Crónicas de los Reyes de Castilla, ed. Cayetano Rosell, Biblioteca de Autores Españoles, 68, Madrid, 1953, p. 382.

${ }^{10} \mathrm{G}$. DAumet, Étude sur l'alliance de la France et la Castille, París, 1898, p. 107.

${ }^{11}$ AGS, Patronato Real, leg. 49, ff. 16-17; L. GaLíndez DE CARVAJAL, Crónica del serenísimo príncipe, p. 411.

${ }^{12}$ L. GAlíndeZ DE CARVAJAL, Crónica del serenísimo príncipe, p. 429; A. GARCía DE Santamaría, Crónica de Juan II, 99, pp. 343-344.

${ }^{13}$ L. FERnÁNDEZ GALlARDO, Alonso de Cartagena. Una biografía política en la Castilla del siglo $X V$, Valladolid, 2002, p. 122.

${ }^{14}$ Así lo menciona: S. PorTEla PAZOS, Decanologio de la SAM iglesia catedral de Santiago de Compostela, Santiago de Compostela, 1944, p. 151, sin indicar fuente, de ahí el matiz de duda.

${ }^{15} \mathrm{~A}$. SAlAZAR, El impacto humanístico de las misiones diplomáticas de Alonso de Cartagena en la corte de Portugal. Entre el medievo y el Renacimiento (1421-1431), en "Medieval Hispanic Studies Presented to Rita Hamilton" (A.D. DEYERMOND ed.), Londres,'1976, pp. 215226, en concreto p. 216.

${ }^{16}$ Para ambas: L. FeRnÁNDEZ Gallardo, Alonso de Cartagena. Una biografía política, pp. 133-227.

${ }^{17}$ L. Galíndez de CARVAJAL, Crónica del serenísimo príncipe., p. 565-567. 
-Alfonso de Egea, entre 1391 y 1392 a Francia ${ }^{18}$, en 1405 a Benedicto $\mathrm{XIII}^{19}$, desde 1407 seguirá en la Curia de Benedicto XIII ${ }^{20}$.

-Alfonso Páez de Santamaría, ante Tamerlán en $1403^{21}$.

-Alfonso de Palenzuela, al papa entre 1456 y $1457^{22}$, de nuevo entre 1459 y $1460^{23}$, a Aragón y el príncipe de Viana en $1460^{24}$, a Inglaterra en $1467^{25}$, y de nuevo en $1471^{26}$. $1447^{28}$.

-Alfonso de Segura, en Portugal en $1445^{27}$ y tal vez en Curia en

-Alfonso de Velasco, ante la reina Navarra en $1440^{29}$.

-Alfonso de Villarreal ante el papa en $1463^{30}$, y de nuevo entre 1471 y $1484^{31}$.

-Alfonso González de Herrera, en la Curia desde $1439^{32}$ al menos hasta $1442^{33}$.

-Alfonso Sánchez de Madrigal, en Nápoles ante el rey de Aragón en $1443^{34}$.

${ }^{18}$ G. DAUMET, Étude sur l'alliance de la France, p. 60; L. SUÁREZ FERnÁndeZ, Algunos datos sobre política exterior de Enrique III, "Hispania", 10-40 (1950), pp. 539-593, p. 545.

${ }^{19}$ L. SUÁreZ FERNÁNDEZ, Castilla, pp. 54-56.

${ }^{20}$ J.M. NIETO SORIA, Iglesia y génesis del Estado moderno en Castilla (1369-1480), Madrid, 1993, p. 297. Como se verá, los dos regentes de Juạ II (la reina Catalina de Lancảster y el infante Fernando) llegaron a desarrollar una diplomacia separada, con sus propios embajadores y enviados.

${ }^{21}$ L. SUÁreZ FernándeZ, Algunos datos, p. 589.

${ }^{22}$ Archivio Segreto Vaticano (en adelante ASV), Reg. Vat., 457, f. 132v; J.M. NIETO SoRIA, Enrique IV de Castilla y el pontificado (1454-1474), "En la España Medieval”, 19 (1996), pp. $167-238$, p. 193.

${ }^{23}$ J.M. NIETO SORIA, Enrique IV, p. 194.

${ }^{24}$ D. ENRÍ́uez DEL CASTILlO, Crónica de Enrique IV, ed. A. Sánchez Martín, Valladolid, 1994, cap. XXVI, p. 172.

${ }^{25}$ AGS, Patronato Real, leg. 52, $\mathrm{n}^{\mathrm{0}} 16$.

${ }^{26}$ M.A. OCHOA BRUN, Historia, I, p. 278.

${ }^{27}$ AGS, Patronato Real, leg. 49, n. ${ }^{\circ} 28$.

${ }^{28}$ O. VILLARROEL GONZÁLEZ, El rey y el papa..., p. 275.

${ }^{29} \mathrm{~A}$. DE PALENCIA, Gesta hispaniensia ex annalibus suorum dierum collecta, ed. R.B. Tate y J. Lawrence, Madrid, 1998, I, p. 3.

${ }^{30} \mathrm{~A}$. LÓPEZ FERNÁNDEZ, El franciscanismo en España durante los pontificados de Calixto III, Pío II y Pablo II a la luz de los documentos vaticanos, "Archivo Ibero-Americano", 3 (1943), pp. 496-570, p. 546. p. 256 .

${ }^{31} \mathrm{~J}$. García ORO, Francisco de Asís en la España medieval, Santiago de Compostela, 1988,

${ }^{32}$ AGS, Estado-Francia, K-1711, ff. 417r-421r.

${ }^{33}$ Archivo de la Casa Ducal de Alba, leg. 222-5, sin número de documento; publicado por J.M. NIETO SORIA, Dinero y política en torno a una vacante episcopal: la provisión de Toledo en 1442, en "Escritos dedicados a José María Fernández Catón" (M. DoMíNGUEZ GARCÍA, M.C. DíaZ Y DÍAZ, M. DíaZ DE BUSTAMANTE, Coords), II, 2004, pp. 1059-1071, en concreto pp. 1067-1069.

${ }^{34} \mathrm{~V}$. Beltrán de HeRedia, Cartulario de la Universidad de Salamanca, Salamanca, 1970 , I, p. 481 y doc. 101 , pp. 688-689. 
-Álvaro de Isorna, en Portugal en $1414^{35}$, en Aragón en $1415^{36}$, en las vistas de Perpiñán ese mismo año ${ }^{37}$, en Curia en $1421^{38}$ y en el Concilio de Basilea entre 1434 y $1439^{39}$.

-Álvaro Martínez, en Francia en $1395^{40}$.

-Antonio de Ceínos, ante el papa de Roma en $1405^{41}$ y ese mismo año ante Benedicto XIII ${ }^{42}$.

-Antonio Jacobo de Veneris, ante el papa en $1464^{43}$.

-Diego de Anaya, embajador en el Concilio de Constanza desde $1417^{44}$, embajador en Francia junto a Rodrigo de Bernal entre 1419 y $1420^{45}$. -Diego de Bedán, en Aragón en $1422^{46}, 1424^{47}$, y $1425^{48}$.

-Diego Enríquez del Castillo, en 1465, a Navarra ante el príncipe de Navarra, conde de Foix ${ }^{49}$.

-Diego de Saldaña, enviado al papa entre 1454 y $1459^{50}$.

-Diego Gómez de Fuensalida, en 1411 en Aragón ${ }^{51}$, en el Concilio de Constanza en $1414^{52}$, en las vistas de Perpiñán en $1415^{53}$.

-Domingo Fernández, en Francia en $1395^{54}$.

-Enrico Schulte, en el Concilio de Siena en $1424^{55}$.

-Fernán López de Villaescusa, en 1454 en Portugal ${ }^{56}$.

${ }^{35}$ M.A. OCHOA BRUN, Historia, I, p. 252.

${ }^{36}$ L. GalíndeZ DE CARVAJAL, Crónica del serenísimo príncipe, p. 382.

${ }^{37}$ L SUÁREZ FERNÁNDEZ, Castilla, p. 77.

${ }^{38}$ L. Galíndez de CaRvajal, Crónica del serenísimo príncipe, p. 403.

${ }^{39}$ O. ViLLARROEL GONZÁLEZ, El rey y el papa, p. 188-200. L. GalíndEZ DE CARVAJAL, Crónica del serenísimo príncipe, p. 515.

${ }^{40}$ Biblioteca Nacional de España (en adelante BNE), ms. 13236, f. 14 v; L. SUÁREZ FERNÁNDEZ, Algunos datos, p. 549.

${ }^{41}$ AGS, Estado-Castilla, leg. 1-1, f. 18; documento publicado por L. SUÁREZ FERNÁNDEZ, Castilla, pp. 252-253.

${ }^{42}$ L. SUÁREZ FERnÁNDEZ, Castilla, pp. 54-55 y documentos en 267-269.

${ }^{43}$ MA. OCHOA BRUN, Historia, I, p. 284.

${ }^{44}$ AGS, Patronato Real, caj, 21, n. ${ }^{\circ} 9$, n. ${ }^{\circ} 3$.

${ }^{45}$ Archivo Capitular (en adelante AC) de Cuenca, Secretaría, Actas capitulares, Libro III, f. 56-v, y L. GALINDEZ DE CARVAJAL, Crónica del serenísimo príncipe, p. 382.

${ }^{46}$ Archivo de Villa (en adelante AV) Madrid, Secretaría, 2-311-33.

${ }^{47}$ L. GALÍNDEZ DE CARVAJAL, Crónica del serenísimo príncipe, p. 428.

${ }^{48}$ Ibídem, pp. 430-431.

${ }^{49}$ D. EnRíQuez del CASTILlo, Crónica, cap. LXXXIII, p. 252.

${ }^{50}$ ASV, Reg. Vat, 457, f. 132v; J.M. NIETO SORIA, Enrique IV, p. 193.

${ }^{51}$ L. GalíndeZ DE CARVAJAL, Crónica del serenísimo príncipe, pp. 337 y 339.

${ }^{52}$ L. SUÁREZ FERnÁNDEZ, Castilla, p. 70.

${ }^{53}$ J. GoÑ I GAZTAMBIDE, Los españoles en el Concilio de Constanza, I, "Hispania Sacra", 15 (1962), pp. 253-386, en concreto p. 265.

${ }^{54} \mathrm{G}$. DAUMET, Étude sur l'alliance de la France, p. 63.

${ }^{55}$ M.C. MiLLER, Participation at the council of Pavia-Siena (1423-1424), "Archivum Historiae Pontificiae", 22 (1984), pp. 389-406, en concreto p. 406.

${ }^{56}$ D. EnRíQuez del CASTILlo, Crónica, cap. XIV, p. 155. 
-Fernando de Frías, en 1454 en Portugal ${ }^{57}$.

-Fernando de Illescas, ante el papa en 1396 y $1397^{58}$, en Francia en $1397^{59}$, al emperador en $1399^{60}$, y al Concilio de Constanza en $1417^{61}$.

-Fernando García, en 1409 al papa ${ }^{62}$.

-Fernando Martín Dávalos, en 1417 al Concilio de Constanza ${ }^{63}$.

-Fernando (criado del arzobispo de Toledo), a Francia en $1398^{64}$.

-Fortún Velázquez de Cuéllar, en la Curia en $1443^{65}$, a Francia en $1454^{66}$, al papa en $1460^{67}$.

-Francisco Fernández de Toledo, embajador en Curia en $1449^{68}$, y de nuevo ante el papa entre 1465 y $1470^{69}$.

-Fray Francisco de Soria, ante el rey de Navarra ${ }^{70}$.

-Gil Fernández de Alfaro, embajador en la Curia en $1434^{71}$.

-Gonzalo Sánchez, en 1409 al papa ${ }^{72}$.

-Gonzalo de Santamaría, en el Concilio de Basilea desde $1436^{73}$.

-Gutierre de Toledo, en 1420 en la Curia ${ }^{74}$ y en 1429 en Aragón ${ }^{75}$. $1444^{76}$ y $1445^{77}$.

-Juan Alfonso de Cuenca, en Sicilia ante el rey de Aragón entre

${ }^{57}$ A. DE PALENCIA, Gesta hispaniensia, I, p. 104.

${ }^{58}$ L. SUÁREZ FERNÁNDEZ, Castilla, pp 31-34.

${ }^{59} \mathrm{G}$. DAUMET, Étude sur l'alliance de la France, p. 66; L.V. Díaz MARTíN, Los inicios de la política internacional de Castilla (1360-1410), en Realidad e imágenes del poder. España a fines de la Edad Media”, (A. RUCQUOI coord.), Valladolid, 1988, pp. 57-85, en concreto p. 77.

${ }^{60}$ A. LóPEZ, Fray Fernando de Illescas, p. 248.

${ }^{61}$ AGS, Patronato Real, caj, 21, n. ${ }^{\circ} 9$, n. ${ }^{\circ} 3$..

${ }^{62}$ ASV, Reg. Avin., 332, ff. 4 v-5 r; documento publicado por L. SUÁREZ FERNÁNDEZ, Castilla, p. 278.

${ }^{63}$ AGS, Patronato Real, caj, 21, n. ${ }^{0}$ 9, n. ${ }^{0} 3$.

${ }^{64}$ L. SUÁREZ FERNÁNDEZ, Castilla, pp. 38-39.

${ }^{65}$ ASV, Reg. Vat., 367, f. 165r.

${ }^{66}$ A. PAlEnCia, Gesta, I, p. 101.

${ }^{67}$ PIO II, Commentarii rerum memorabilium, ed. bilingüe latín-inglés a cargo de M. Meserve y M. Simonetta, Cambridge, 2007, II, p. 282. Se refiere a él como "Legionemsem episcopus".

${ }^{68} \mathrm{E}$. Benito RuAno, Toledo en el siglo XV. Vida política, Madrid, 1961, pp. 52-53.

${ }^{69}$ J.M. NIETO SORIA, Enrique IV, p. 196.

${ }^{70}$ L. GaLÍNDEZ DE CARVAJAL, Crónica del serenísimo príncipe, p. 452.

${ }^{71}$ A. García de Santamaría, Crónica de don Juan II, ed. Antonio Paz y Meliá, Madrid, 1891, no 99, de la Colección de Documentos Inéditos para la Historia de España, pp. 81 - 464, p. 405.

${ }^{72}$ L. SUÁREZ FERNÁNDEZ, Los Trastámara de Castilla y Aragón en el siglo XV, tomo XV de la "Historia de España" dirigida por Menéndez Pidal, Madrid, 1964, p. 38.

${ }^{73}$ L. SuÁreZ FernándeZ, Castilla, p. 356, doc. 128.

${ }^{74}$ L. GalínDEZ DE CARVAJAL, Crónica del serenísimo príncipe, p. 388.

${ }^{75}$ Ibídem, p. 463.

${ }^{76}$ Biblioteca de la Real Academia de la Historia (en adelante BibRAH), colección Salazar y Castro, 9/706, f. 45; publicado en: I. PASTOR BODMER, Grandeza y tragedia de un valido. La muerte de don Alvaro de Luna, Madrid, 1992, II, p. 55.

${ }^{77}$ BibRAH, colección Salazar y Castro, K 81, ff. 61-74; publicado en: I. Pastor Bodmer, Grandeza, II, pp. 71-78; citando: Archivo de la Corona de Aragón, 2943, ff, 125-137. 
-Juan Alfonso de Madrid, al papa en $1405^{78}$.

-Juan Alfonso de Mella, en la Curia al menos en $1423^{79}$ y $1433^{80}$.

-Juan Alfonso de Zamora, desde 1421 en Portugal junto a Alfonso de Cartagena ${ }^{81}$, y en el Concilio de Basilea en $1433^{82}$.

-Juan Álvarez de Toledo, en Curia hasta $1429^{83}$.

-Juan de Arce, ante el papa en $1457^{84}$.

-Juan Carrillo, embajador en Francia en $1435^{85}$.

-Juan de Cervantes, en la Curia desde $1419^{86}$, en el Concilio de Siena entre 1423 y $1424^{87}$, en Basilea en $1433^{88}$.

-Fray Juan del Corral, en Inglaterra entre 1430 y $1431^{89}$, y en el Concilio de Basilea desde $1434^{90}$.

-Juan García Fernández, en 1399 ante el emperador ${ }^{91}$.

-Juan García, en la Curia durante varios años alrededor de $1445^{92}$.

-Juan González de la Maina, en el Concilio de Basilea desde $1434^{93}$.

-Juan de Illescas, ante el papa en $1406^{94}$, en Portugal desde $1409^{95}$.

-Juan de Madrigal, ante Benedicto XIII en Aviñón en $1395^{96}$, de nuevo ante el papa en 1416 en Peñíscola ${ }^{97}$.

${ }^{78}$ AGS, Estado-Castilla, leg. 1-1, f. 44. L. SuÁREZ FernándEZ, Castilla, p. 55.

${ }^{79} \mathrm{ASV}$, Reg. Vat., 354, ff. 167v-168r; publicado en L. SUÁREZ FERNÁNDEZ, Castilla, pp. 319-320; y en V. BELTRÁN DE HEREDIA, Bulario de la Universidad de Salamanca, Salamanca, 1966, II, doc. 660, p. 223.

${ }^{80}$ V. BELTRÁN DE HEREDIA, Bulario, II, doc. 855, p. 374.

${ }^{81}$ AGS, Patronato Real, leg. 49, ff. 16-17.

${ }^{82} \mathrm{~L}$. SERRANo, Los conversos don Pablo de Santa María y don Alfonso de Cartagena. Obispos de Burgos, gobernantes, diplomáticos y escritores, Madrid, 1942, pp. 134-135; citando: Protocolo, f. 61.

${ }^{83}$ V. Beltrán de HeREdia, Bulario, II, doc. 807, p. 332.

${ }^{84}$ J.M. NIETO SORIA, Enrique IV, p. 194.

${ }^{85} \mathrm{G}$. DAUMET, Étude sur l'alliance de la France, p. 85.

${ }^{86} \mathrm{~V}$. BELTRÁn DE HEREDIA, Bulario, II, doc. 583, pp. 130-131.

${ }^{87}$ M.C. Miller, Participation, p. 401; W. BrandMüller, Das Konzil von Pavia-Siena 1423-1424, Münster, 1968/1976 II', p. 211.

${ }^{88}$ L. SeRrano, Los conversos, p. 134-135; citando: Protocolo, f. 61.

${ }^{89}$ L. GALÍndeZ DE CARVAJAL, Crónica del serenísimo príncipe, pp. 482 y 494.

${ }^{90}$ L. BARRIENTOS, Refundición de la crónica del halconero, Madrid, 1946, pp. 150-154.

${ }^{91}$ A. LÓPEZ, Fray Fernando de Illescas, p. 248.

${ }^{92}$ ASV, Reg. Lat., 420, ff. 303 v-304 v.

${ }^{93}$ L. BARRIENTOS, Refundición, pp. 150-154.

${ }^{94}$ M.A. OCHOA BRUN, Historia, p. 246.

${ }^{95}$ L.V. DíAz MARTín, Los inicios, p. 80.

${ }^{96}$ E. ZARAGOZA PASCUAL, Los generales de la congregación de San Benito de Valladolid. I Los priores (1390-1499), Silos, 1973, p. 57.

${ }^{97}$ Ibídem. 
-Juan Martínez Contreras, en Curia y el Concilio de Siena en 1423 y $1424^{98}$ y en Aragón entre 1430 y $1431^{99}$.

-Juan de Medina, ante el papa en $1465^{100}$.

-Juan Rodríguez de Villalón, en 1409 ante el papa ${ }^{101}$, en 1411 en Portugal $^{102}$, en el Concilio de Constanza en $1417^{103}$.

-Juan Serrano, en Portugal en $1392^{104}$, y de nuevo en $1393^{105}$.

-Juan de Tordesillas, en Roma ante el papa de la obediencia romana en $1400^{106}$, en las vistas de Morella en $1414^{107}$.

-Juan de Torquemada, en el Concilio de Basilea en $1432^{108}$.

-Lope de Mendoza, a Francia en $1393^{109}$, en ante el papa $1396^{110}, y$ en Francia en $1397^{111}$.

-Luis de Acuña, en 1463 a Francia ${ }^{112}$.

-Luis González de Atienza, ante Alfonso V en $1451^{113}$, en $1454^{114}$, y de nuevo en $1456^{115}$, ante el papa en entre 1458 y $1474^{116}$, en Francia y el ducado de Bretaña en $1464^{117}$, y en Francia en $1470^{118}$.

-Lope de Galdo, en el Concilio de Basilea desde $1434^{119}$.

\footnotetext{
${ }^{98}$ W. Brandmüller, Das Konzil, II, p. 212; M.C. Miller, Participation, p. 404.

${ }^{99} \mathrm{AC}$ de Sigüenza, n. ${ }^{\circ} 419$, desaparecido; también en T. MiNGUELLA Y ARNEDO, de la diócesis de Siguienza y sus obispos, Madrid, 1912 , suplemento no 141 . Véase: Colección de documentos inéditos del Archivo de la Corona de Aragón, vol. XXXVII.

${ }^{100}$ Memorias de Enrique IV de Castilla, Madrid, 1835-1913, II, p. 502.

${ }^{101}$ ASV, Reg. Avin., 332, ff. 4 v-5 r; documento publicado por L. SUÁREZ FERNÁNDEZ, Castilla, pp. 225-226.

${ }^{102}$ M.F. DE BARROS SOUSA, Quadro elementar das relaçoes politicas e diplomaticas de Portugal com as diversas potencias do mundo desde o principio da monarchia portuguesa até aos nossos dias, París, 1842 , I, p. 287 y ss.

${ }^{103}$ AGS, Patronato Real, caj, 21, n. ${ }^{\circ}$ 9, n. ${ }^{\circ} 3 .$.

${ }^{104}$ L.V. Díaz MARTín, Los inicios, p. 76.

${ }^{105}$ AGS, Patronato Real, leg. 47, $\mathrm{n}^{\mathrm{o}}$ 29; P. LÓPEZ DE AYALA, Crónica del rey don Enrique tercero de Castilla e de León, en el tomo II de las Crónicas de los Reyes de Castilla, ed. Cayetano Rosell, Biblioteca de Autores Españoles, 68, Madrid, 1953, p. 200.

${ }^{106}$ L. SUÁrEZ FERNÁNDEZ, Castilla, p. 44.

${ }^{107}$ L. GALÍNDEZ DE CARVAJAL, Crónica del serenísimo príncipe, p. 361.

${ }^{108}$ J. HALler, Protokolle des Concils der Jahre 1431-1433, Basilea, 1897, II, p. 203.

${ }^{109}$ L.V. DíAz MARTín, Los inicios, p. 77. p. 200 .

${ }^{110}$ G. DAUMET, Étude sur l'alliance de la France, p. 64; L. SuÁREZ FERNÁNDEZ, Castilla,

${ }^{111}$ L. SUÁREZ FernÁNDEZ, Castilla, p. 34.

${ }^{112}$ G. DAUMET, Étude sur l'alliance de la France, p. 107.

${ }^{113}$ J. ZURITA, Anales de Aragón, edición electrónica en formato pdf de la Institución Fernando el Católico, accesible a través de la página web de la mencionada institución, VII, libro XVI, capítulo I.

${ }^{114}$ Ibídem, capítulo XXVIII.

${ }^{115} \mathrm{R}$. SALICRÚ I LLUCH, Documents per a la història de Granada del regnat d'Alfons el Magnànim (1416-1458), Barcelona, 1999, doc. 413.

${ }^{116}$ M.A. OCHOA BRUN, Historia, I, p. 279. Indica que lo fue ante Pío II y Sixto IV.

${ }^{117}$ G. DAUMET, Étude sur l'alliance de la France, p. 109.

${ }^{118}$ M.A. OCHOA BRUN, Historia, I. p. 279.

${ }^{119}$ L. BARRIENTOS, Refundición, p. 150-154.
} 
-Fray Luis de Valladolid, en el Concilio de Constanza en $1417^{120}$, en Aragón en $1422^{121}$.

-Martín de Vargas, en Aragón en $1430^{122}$.

-Pablo de Santa María, en 1415 en las vistas de Perpiñán ${ }^{123}$. $1424^{124}$.

-Pedro Alfonso de Valladolid, en el Concilio de Siena entre 1423 y

-Pedro de Bocanegra, ante el rey de Navarra en $1429^{125}$, en Aragón en $1430^{126}$, y en la Curia en $1436^{127}$.

-Pedro de Castilla, en Aragón en $1430^{128}$

-Pedro de Cervantes, en Aragón en $1444^{\mathrm{i} 29}$.

-Pedro Fernández, ante el papa en $1409^{130}$.

-Pedro Fernández de Cámara, en Inglaterra en $1403^{131}$, ante el papa en $1406^{132}$, en el Concilio de Constanza en $1417^{133}$, en Curia hasta $1422^{134}$.

-Pedro Fernández de Frías, en Portugal en $1402^{135}$.

-Pedro Fernández de Solís en 1471 en Roma ${ }^{136}$.

-Pedro González de Medina, en 1405 ante el papa ${ }^{137}$.

-Pedro González de Mendoza, en 1462 a Navarra ${ }^{138}$ y en 1464 en las vistas de Fuenterrabía con el rey de Francia ${ }^{139}$.

-Pedro Ramírez, en Aragón en $1430^{140}$.

-Remón, monje cisterciense, ante el conde de Armagnac en $1431^{141}$.

${ }^{120}$ AGS, Patronato Real, caj, 21, n. ${ }^{\circ}$ 9, n. ${ }^{\circ} 3$.

${ }^{121}$ L. GalíndeZ de CARVAJAL, Crónica del serenísimo príncipe, p. 419.

${ }^{122}$ Colección de documentos inéditos del Archivo de la Corona de Aragón (en adelante CODOINCA), XXXVII, Barcelona, 1869, p. 125.

${ }^{123}$ L. SUÁREZ FERNÁNDEZ, Castilla, p. 77.

${ }^{124}$ M.C. Miller, Participation, p. 400.

${ }^{125}$ L. GALÍNDEZ DE CARVAJAL, Crónica del serenísimo príncipe, p. 452.

${ }^{126}$ CODOINCA, XXXVII, p. 125.

${ }^{127}$ V. BELTRÁN DE HEREDIA, Bulario, II, doc. 913, p. 417.

${ }^{128}$ CODOINCA, XXXVII, p. 125.

${ }^{129}$ BibRAH, colección Salazar y Castro, 9/706, ff. 181-207.

${ }^{130}$ J.M. NiETO SORIA, Iglesia, p. 297.

${ }^{131}$ J. GoÑ I GaZTAMBIDE, Los españoles en el Concilio de Constanza, II, "Hispania Sacra", 16 (1963), pp. 106-200, en concreto p. 197.

${ }^{132}$ L. SUÁREZ FERNÁNDEZ, Castilla, p. 243.

${ }^{133}$ AGS, Patronato Real, caj, 21, n. ${ }^{\circ}$ 9, n. ${ }^{\circ} 3$.

${ }^{134}$ V. BELTRÁN DE HEREDIA, Bulario, II, doc. 653, pp. 216-217.

${ }^{135}$ L. SUÁREZ FERNÁNDEZ, Algunos datos, p. 578.

${ }^{136}$ D. ENRÍQUez DEL CASTILlO, Crónica cap. CVII, p. 295. D. VALERA, Memorial de diversas hazañas. Crónica de Enrique IV, ed. J. Torres Fontes, Murcia, 1946, cap. XXV, p. 90.

${ }^{137}$ AGS, Estado-Castilla, leg. 1-1, f. 16, publicado en L. SuÁREZ FERNÁNDEZ, Castilla, pp. 271-273.

${ }^{138}$ D. ENRÍQUeZ DEL CASTILlo, Crónica, cap. LIII, p. 207.

${ }^{139} \mathrm{G}$. DAUMET, Étude sur l'alliance de la France, p. 107.

${ }^{140}$ CODOINCA, XXXVII, p. 30.

${ }^{141}$ L. GaLínDEZ DE CARVAJAL, Crónica del serenísimo príncipe, p. 492. 
-Rodrigo Bernal, embajador en Francia entre $1419^{142}$ y $1420^{143}$.

-Rodrigo Díaz de Torres, en 1416 ante el papa ${ }^{144}$.

-Rodrigo Gutiérrez de Barcenilla, en Curia en $1432^{145}$.

-Rodrigo Martínez de Lara en 1407 ante el papa ${ }^{146}$.

-Rodrigo Sánchez de Arévalo, en el Imperio entre 1443 y $1444^{147}$, 1454 en Francia ${ }^{148}$, ante el papa entre 1456 y $1459^{149}$, y de nuevo ante el papa entre 1459 (Congreso de Mantua ${ }^{150}$ ) y $1463^{151}$.

-Rodrigo de Vergara, ante el papa entre 1465 y $1469^{152}$.

-Ruy García de Villaquirán, en la Curia en $1423^{153}$.

-Sancho de Rojas (el posterior arzobispo de Toledo), en 1399 a Portugal $^{154}$, en 1411 a Âragón ${ }^{155}$, de nuevo en Aragón en $1415^{156}$.

-Sancho de Rojas (el posterior obispo de Córdoba), en la Curia y el Concilio de Siena en $1424^{157}$, en Aragón y Navarra en $1429^{158}$ y en Inglaterra entre 1430 y $1431^{159}$.

-Sancho López de Vesco, en Aragón en $1424^{160}$.

-Suero Solís, en 1464 ante el papa ${ }^{161}$.

${ }^{142}$ AC de Cuenca, Secretaria, Actas capitulares, Libro III, f. 56-v.

${ }^{143}$ L. GALÍNDEZ DE CARVAJAL, Crónica del serenísimo príncipe, p. 382.

${ }^{144}$ L. SuÁREZ FERNÁNDEZ, Castilla, p. 83.

${ }^{145}$ Ibídem, p. 504. 56.

${ }^{146}$ Crónica de la provincia franciscana de Santiago, ed. M. Castro Castro, Madrid, 1971, p.

${ }^{147}$ V. Beltrán DE Heredia, Cartulario, I, p. 384.; L. SeRrano, Los conversos, p. 212; citando: Reg. 12, f. 74 y 117; Reg. 5, ff. 117 y 130.

${ }^{148}$ J.M. LABOA, Rodrigo Sánchez de Arévalo, alcaide de sant'Angelo, Madrid, 1973, p. 54.

${ }^{149}$ ASV, Reg. Vat., 457, f. 104; J.M. NIETO SORIA, Enrique IV, p. 192.

${ }^{150}$ J.M. LABOA, Rodrigo, p. 72. p. 147 .

${ }^{151}$ Ibídem, p. 76-77; J. Torres Fontes, Itinerario de Enrique IV de Castilla, Murcia, 1953,

${ }^{152}$ Memorias de don Enrique IV, II, p. 502.

${ }^{152} \mathrm{AC}$ de Toledo, A.8.L.1.8, $1^{\mathrm{a}}$ y $2^{\mathrm{a}}$; también en BNE, ms. 13018, ff. 168v-169r. Documentos publicados en O. VILLARROEL GONZÁLEZ, Las relaciones entre la Monarquía y el arzobispado de Toledo en época de Juan II de Castilla (1406-1454), Toledo, 2002, pp. 272273.

${ }^{154}$ L.V. DíAZ MARTíN, Los inicios, p. 77.

${ }^{155}$ L. GALíndeZ DE CARVAJAL, Crónica del serenísimo príncipe, p. 336.

${ }^{156}$ Ibídem, p. 382.

${ }^{157}$ ASV, Reg. Vat., 359, ff. 15 rv; documento publicado por L. SUÁREZ FERNÁNDEZ, Castilla, p. 322, quien lo data con dudas en 1424. Se equivoca sin embargo, pues en él se indica que el obispo debía acudir al Concilio futuro refiriénose sin duda a Pavia-Siena, con lo cual sería anterior a la apertura del mismo, siendo datable a principios de 1423, así lo hace W. BRANDMÜLLER, Das Konzil, II, p. 59.

${ }^{158}$ Ibídem, p. 471.

${ }^{159}$ L. GaLínDEZ DE CARVAJAL, Crónica del serenísimo príncipe, pp. 482 y 494.

${ }^{160}$ A. García De SANTAMARÍA, Crónica, pp. 333-334.

${ }^{161}$ D. EnRíQuez del CASTILlo, Crónica, cap. LXII, p. 216. 
-Vasco Ramírez de Guzmán, embajador en Francia en $1436^{162}$. a Francia ${ }^{164}$.

-Vicente Arias de Balboa, en 1395 ante el papa ${ }^{163}$, y ese mismo año

-Alfonso, en el Concilio de Siena y en la Curia en $1423^{165}$.

-Y el prior de Guisando, en 1405 ante el papa ${ }^{166}$.

\section{LOS DESTINOS Y LAS TAREAS ENCOMENDADAS}

Tan extensa lista de delegados diplomáticos por parte de los reyes de Castilla nos indica, claramente, cómo la monarquía castellana se imbricó de forma activa en la política europea del momento, participando en todos los ámbitos donde sus intereses pudiesen estar en juego. En este sentido, se seguía la línea ya marcada por los primeros monarcas Trastámara ${ }^{167}$. La comunicación con unos u otros ámbitos nos muestra también, claramente, cuáles eran las principales preocupaciones para Castilla. Veamos, siguiera sucintamente, cómo y por qué se llevaron a cabo esas acciones diplomáticas. No entraremos en el análisis pormenorizado de cada una de las embajadas, pues sería demasiado prolijo y nos alejaría demasiado del objetivo principal del trabajo $^{168}$.

\subsection{Francia}

Como es sabido, Francia venía siendo, ya a principios del siglo XV, un tradicional aliado del reino de Castilla. La ayuda prestada por este reino a Enrique II a la hora de acceder al trono fue, evidentemente, fundamental a la hora de acordarse la alianza, dado lo mucho que le debía, y la colaboración había sido estrecha y fructífera para ambos ${ }^{169}$.

\footnotetext{
${ }^{162}$ AGS, Estado-Francia, K-1711, f. 198v; documẹto publicado por L. SUÁREZ FERNÁNDEZ, Castilla, p. 361, este autor ya comentó la importancia de esta embajada para unificar criterios, pp. $128-129$.

${ }^{163} \mathrm{~V}$. Beltrán de Herecia, Cartulario, I, p. 187.

${ }^{164}$ G. DAUMET, Étude sur l'alliance de la France, p. 63.

${ }^{165}$ W. BRANDMÜller, Das Konzil, II, p. 215.

${ }^{166}$ AGS, Estado-Castilla, leg. 1-1, f. 52; documento publicado por L. SUÁREZ FERNÁNDEZ, Castilla, p. 269.

${ }^{167}$ L.V. DÍAZ MARTíN, Los inicios, p. 63.

${ }^{168}$ Remito para ello, al menos en lo tocante al reinado de Juan II, a: O. VILLARROEL GONZÁLEZ, El rey y la Iglesia castellana. Relaciones de poder con Juan II (1406-1454) (en prensa), capítulo segundo, apartado 5.

${ }^{169}$ G. DAUMET, Étude sur l'alliance de la France; J. CALMETTE, J., La formation de la unité espagnole, París, 1946; L. SUÁREZ FERNÁNDEZ, Navegación y comercio en el golfo de Vizcaya. Un estudio de la política marinera de la casa de Trastámara, Madrid 1958; y sobre sus momentos finales: L. SUÁREZ FERNÁNDEZ, Política internacional de Isabel la Católica, 2 vols. Valladolid, 1965. Además, sobre un aspecto concreto del entorno francés, como es el de los condes de Armagnac, véase: C. OLIVERA SERRANO Los condes de Armagnac y la diplomacia castellana del siglo XV (1425-1474), "En la España Medieval”, 16 (1993), pp. 189-222.
} 
De esta forma, a lo largo de los tres reinados analizados las comunicaciones con Francia son fluidas. Con Enrique III no hay que esperar mucho. Ya en 1391 se envío el primer embajador, Alfonso de Egea, con poco margen de tiempo en comparación con los embajadores franceses que acudieron a Castilla por la muerte de Juan I y para confirmar las alianzas existentes ${ }^{170}$. Sería, sin embargo, el año 1395 en el que el envío de eclesiásticos como embajadores a Francia se relanzase con fuerza: Álvaro Martínez, Domingo Fernández y Vicente Arias de Balboa. La labor del primero de ellos (por razones del Cisma y para negociar tanto en Francia como en la Curia de Aviñón ${ }^{171}$ ) nos marca la línea principal que seguiría Enrique III: buscar una solución de forma conjunta con Francia.

Esta labor por parte de Enrique III no cabe duda que animó esas relaciones, y con ello el envío de delegados. Entre 1395 y 1398 se enviaron seis enviados eclesiásticos (Domingo Fernández, Vicente Arias de Balboa, Fernando de Illescas, Lope de Mendoza, Álvaro Martínez y el maestro Fernando). La sustracción de obediencia, curiosamente, detuvo los envíos de embajadores. Sin duda la parte más difícil de acordar fue la sustracción, no la actuación posterior. El fracaso de la sustracción supondría un nuevo envío, ya en 1405, de una nueva misión en la que aparece un eclesiástico: Alfonso de Alcocer.

El reinado de Juan II supuso un cierto cambio en las misiones diplomáticas. Lo más llamativo es que hasta 1419 no detectamos una nueva misión formada por eclesiásticos, en este caso Diego de Anaya y Rodrigo Bernal. Con ella, además, nos encontramos ante una respuesta a la enviada por el delfín y encabezada por Beltrán Champion para acordar el envío de barcos castellanos para trasladar las tropas escocesas a Francia ${ }^{172}$. Esta embajada, en la que también acudía Alfonso de Pimentel ${ }^{173}$, permaneció allí al menos hasta 1420, pues no regresaron a la Corte castellana hasta el día después del Golpe de Tordesillas ${ }^{174}$.

Con esto nuevamente se abre un largo intermedio en el que desaparece la participación eclesiástica en embajadas a Francia. Y no es baladí el hecho de que sea nuevamente en el contexto de los problemas que padecía la Iglesia en el que los encontremos. En concreto en 1435 fue enviado Juan Carrillo ante Carlos VII. Era la respuesta a la misión del arzobispo de Tolosa en Madrid, donde fueron fastuosamente recibidos ${ }^{175}$. Nuevamente la situación de la Iglesia activaba el envío de embajadores eclesiásticos a Francia. Tan sólo un año

${ }^{170}$ P. LÓPEZ DE AyALA, Crónica, pp. 174-175.

${ }^{171}$ L. SUÁREZ FERNÁNDEZ, Algunos datos, p. 545.

${ }^{172} \mathrm{G}$. DAUMET, Étude sur l'alliance de la France, pp. 73-74.

${ }^{173}$ Ibídem.

${ }^{174}$ L. GALÍNDEZ DE CARVAJAL, Crónica del serenísimo príncipe, p. 382.

${ }^{175}$ Véase el uso político de la misma en O. VILLARROEL GONZÁLEZ, El rey y la Iglesia castellana, capítulo tercero, apartado 2.5.; también, de forma más parcial, en mis anteriores obras: Las relaciones entre la monarquía, pp. 83-84; y Pedro de Castilla (1394-1461): un obispo de Osma y sus relaciones con la Monarquia, "Celtiberia", 95 (2001), pp. 132-162, en concreto pp. 145-146. 
después, también por cuestiones del Concilio de Basilea, fue enviado Vasco Ramírez de Guzmán ante Carlos VII, en busca de una posición común en el Concilio ${ }^{176}$.

Durante el reinado de Juan II no encontramos más misiones a Francia. Habría que esperar a los primeros años de Enrique IV para encontrar la remisión de eclesiásticos. Lógicamente, ante el cambio de reinado, sería para confirmar las alianzas, misión en la que participó Fortún Velázquez de Cuéllar en 1454. Las vistas de Fuenterrabía serían, sin duda, el encuentro diplomático de la época entre ambos reinos que más eclesiásticos al servicio regio puso en juego. En concreto Alfonso Carrillo, Luis de Acuña y Pedro González de Mendoza. Y no es baladí el hecho de que sean prelados los tres. Para embajadas normales, sin presencia de los monarcas, se recurrió, durante el reinado de Enrique a Luis González de Atienza que, como hemos visto, marchó dos veces a Francia.

\subsection{Inglaterra}

El envío de embajadores a Inglaterra, en cambio, tiene unos objetivos claramente distintos. La existencia de un cierto vínculo familiar, por el matrimonio de Catalina de Lancáster y Enrique III, una vez que la dinastía Lancáster se asentó en el trono, no cabe duda que facilitó las relaciones; pero se veían frenadas, si no perjudicadas, por dos motivos. En primer lugar la alianza francesa, que hacía que Castilla fuese un posible enemigo (a lo que se uniría la rivalidad comercial). En segundo lugar la inexistencia de una alianza política, que no hacía necesario coordinar acciones en lo tocante a la política eclesiástica en relación al papado y el Concilio, con lo cual ese tipo de misiones, que sí aparecen en Francia, no las encontramos presentes con el reino inglés. En la pacificación existente, qué duda cabe que Catalina de Lancáster modificó en parte la situación, haciendo que Castilla pudiese llegar a acuerdos parciales y treguas con Inglaterra sin tener que pasar por el filtro del rey galo ${ }^{177}$. Una paz que sería reconocida y apreciada por los ingleses y los castellanos, y sostenida pese a los roces que, en algunos momentos, pudiesen surgir entre ellos ${ }^{178}$.

En 1403 ya hemos visto a Pedro Fernández de la Cámara acudir a Inglaterra. No cabe duda que la monarquía prestaba cierta importancia a estas relaciones, como demostraría el hecho de que el enviado fuese secretario

\footnotetext{
${ }^{176}$ Sobre la política castellana con respecto al Concilio véase: V.A. ÁLVAREZ PALENZUELA, La situación europea en época del Concilio de Basilea. Informe de la delegación del reino de Castilla, León, 1992. Más antiguo pero de consulta imprescindible L. SỨREZ FERNÁNDEZ, Castilla; y más reciente, sobre la política castellana entre el papado y el Concilio: O. VILLARROEL GONZÁLEZ, El rey y el papa, pp. 147-186.

${ }^{177}$ A. ECHEVARRÍA, Catalina de Lancáster. Reina regente de Castilla (1372-1418), Hondarribia, 2002, p. 172.

${ }^{178}$ Véase por ejemplo los conflictos en el seno de los Concilios. Para Siena: O. VILLARROEL GoNZÁlEZ, Castilla y el Concilio de Siena (1423-1424): la embajada regia y su actuación, "En la España Medieval", 30 (2007), pp. 131-172, en concreto pp. 162-170; para el de Basilea: L. FERNÁNDEZ GALLARDO, Alonso de Cartagena. Una biografia politica, pp. 133-160.
} 
regio ${ }^{179}$. Durante el reinado de Juan II los contactos fueron también escasos. La falta de enfrentamientos directos, salvo los roces existentes en los Concilios y ante el papa por cuestión de honor ${ }^{180}$, sin duda influyó en ello. El hecho de que incluso en esos momentos de confrontación se plasmase el estado de paz que existía entre ambos reinos nos habla claramente del interés de que no saliese del conflicto diplomático ${ }^{181}$. De hecho, la embajada de 1430 de Sancho de Rojas, obispo de Astorga, y fray Juan del Corral es la única documentada durante este reinado, y se dio como respuesta a otra inglesa en la que se ofrecía firmar una alianza.

Sería con Enrique IV con quien encontremos más datos de presencia de embajadores eclesiásticos en el reino anglosajón. Separadas por tan sólo cuatro años, Alfonso de Palenzuela llevaría a cabo dos misiones ante el monarca inglés, en 1467 y en 1471. El momento es importante, porque supone el cambio de alianza por parte de Enrique IV, dejando de lado a Francia y aliándose con Inglaterra. La embajada de 1471 es dudosa ${ }^{182}$. Sin embargo es interesante y posible, dado que en esos mismos momentos los príncipes Isabel y Fernando sí negociaban con Inglaterra, con quien habrían conseguido, por medio de Juan Ramírez de Lucena, una alianza junto a los duques de Borgoña ${ }^{183}$.

\subsection{El papado y los concilios}

En una ocasión anterior tuve la oportunidad de analizar los representantes diplomáticos del rey ante los diversos papas, así como su actuación ${ }^{184}$. Por ello no se va a hacer aquí un nuevo análisis, sino un breve repaso a los eclesiásticos que participaron en las mismas.

Como se ha podido comprobar, el papado es aquel que en más ocasiones recibe la atención de los reyes castellanos a lo largo del siglo xv. Parece lógico que en este ámbito la presencia de eclesiásticos sea muy nutrida, como efectivamente ocurre, por los numerosos puntos de conexión entre ambos poderes; pero no deja de ser llamativo que en estos casos también haya laicos que desarrollan una gran labor, tanto ante el papa como ante los concilios que se sucedieron a lo largo del siglo (lo que no obsta para que siga habiendo presencia de laicos, con especial relevancia en los marcos conciliares). Sea como fuere, lo cierto es que los embajadores eclesiásticos al papa suponen el cuarenta y tres por ciento de las misiones (sesenta y siete sobre

${ }^{179} \mathrm{~J}$. GoÑ GaZTAmbide, Los españoles en el Concilio de Constanza, II, p. 197.

${ }^{180}$ O. VILLARROEL GONZÁLEZ, El rey y el papa ..., pp. 196-197 y Castilla y el Concilio de Siena ..., , pp. 162-170; y L. FERNÁNDEZ GALLARDO, Álonso de Cartagena. Una biografía política, pp. 133-160.

${ }^{181}$ Por ejemplo, para el Concilio de Siena: O. VILLARroel González, Castilla y el Concilio de Siena, pp. 162-170; W. BRANDMÜLLER, Das Konzil, II, p. 376-378.

${ }^{182} \mathrm{La}$ cita de Ochoa Brun es dudosa y tal vez contenga alguna errata.

${ }^{183}$ AGS, Patronato Real, leg. 12, f. 54.

${ }^{184}$ Véase al respecto: O. VILLARROEL GONZÁLEZ, El rey y el papa ..., pássim. 
ciento cincuenta y seis), con un total de cuarenta y ocho embajadores sobre ochenta y nueve. Es decir, un cincuenta y cuatro por ciento de los embajadores tuvieron entre sus misiones, alguna vez, acudir ante el papado. Como vemos, no cabe duda de que la relevancia del poder pontificio, al menos para la Monarquía castellana, era muy elevada.

Las embajadas, ya con Enrique III, no tenían una única misión, sino que solían tener una cierta extensión temporal, encontrándonos embajadores que permanecen durante mucho tiempo en la Curia pontificia, allí donde se encontrase, o ante el Concilio. Esto, que comprobé ya para época de Juan II $^{185}$ es extensible al resto del periodo, con un importante ejemplo ya en época de Enrique III (Alfonso de Egea).

Además, era usual que en una embajada coincidiesen varias personas, trabajando a la vez en diversas líneas. Esto queda patente, por ejemplo, en la gran embajada de 1405, cuando gran cantidad de eclesiásticos castellanos acudieron a la Curia por orden regia, sirviéndole allí de una forma o de otra, tarde o temprano, todo ello bajo la dirección, aparentemente, de Alfonso de Egea ${ }^{186}$. Posteriormente ocurrirían cosas parecidas, así, cuando Isorna estuvo en Roma en 1422, coincidió con Pedro Fernández de Cámara ${ }^{187}$, y si Juan Alfonso de Mella estaba en 1423 en la Curia ${ }^{188}$, permanecía allí cuando llegaron Ruy García de Villaquirán, Rodrigo de Perea y Juan Martínez Contreras, arzobispo de Toledo ${ }^{189}$. De hecho, a lo largo del reinado la presencia de embajadores ante el papa fue casi constante, y, como vemos, la mayor parte de ellos eran eclesiásticos ${ }^{190}$.

Así pues, la representación regia ante el pontificado fue, con mucho, la más numerosa y fluida. En total, a lo largo del periodo en estudio, fueron cuarenta y ocho los enviados a la Curia en más de sesenta misiones. La mayor parte de ellos, además, tenían cargos menores a obispo, siendo normalmente prebendados. De entre los mencionados sólo había once prelados. A este respecto la tónica que había mostrado el reinado de Juan II vemos que se enmarca dentro de la normalidad ${ }^{191}$. Además, no hay grandes diferencias entre los distintos reinados. En el reinado de Enrique III suponen menos de una cuarta parte (tres de quince), la minoría de edad de sí vemos una notable

\footnotetext{
${ }^{185}$ El rey y la Iglesia castellana, capítulo tercero, apartado 5.2. Véase también El rey y el papa..., pássim.

${ }^{186}$ L. SUÁREZ FERNÁNDEZ, Castilla..., pp. 54-56.

${ }^{187}$ El prelado partió para Castilla el 12 de junio de 1422 (V. BELTRÁn DE HEREDIA, Bulario, II, doc. 656, pp. 218-219), antes lo había hecho Fernández de Cámara, que lo hizo el 12 de marzo (ibídem, doc. 653, pp. 216-217).

${ }^{188} \mathrm{ASV}$, Reg. Vat., 354, ff. 167v-168r; publicado en L. SUÁREZ FERNÁNDEZ, Castilla, pp. 319-320; y' en V. BELTRÁN DE HEREDIA, Bulario, II, doc. 660, p. 223.

${ }^{189}$ Véase al respecto: O. VILLARROEL GONZÁLEZ, Las intervenciones regias en las elecciones episcopales en el reinado de Juan II de Castilla (1456-1454). El caso de los arzobispos de Toledo, "Anuario de Estudios Medievales", 31/1 (2001), pp. 147-190, en concreto pp. 169-179. 330.

${ }^{190} \mathrm{Cfr}$. O. Villarroel GonZÁlez, El rey y el papa, pp. 125-146, 201-216, 262-275 y 3285 .

${ }^{191}$ Cfr. O. VILlarRoel GonZÁLEZ, El rey y la Iglesia castellana, capítulo segundo, apartado
} 
diferencia (cinco de catorce), con el reinado de personal de Juan II se reduce (tres de diecinueve) tónica que se mantiene con Enrique IV (tres de dieciocho). Vemos, pues, cómo el poder regio prefería representarse ante el papa por eclesiásticos de menor relevancia que un prelado, sin duda por las influencias que un obispo (perteneciente la mayor parte de las veces a una gran familia o a sus clientelas ${ }^{192}$ ) podía llevar consigo ajenas a los intereses regios. El aumento de los prelados en época de la minoría de Juan II, sin embargo, se aleja de ese modelo, puesto que, además de aquellos prelados procedentes del servicio regio de Enrique III (Alfonso de Egea y Pablo de Santa María) nos encontramos otras "fechuras" de los regentes, como Diego Gómez de Fuensalida, Álvaro Núñez de Isorna o Juan Vázquez Cepeda. Es decir, los regentes buscaban la colaboración de sus fieles en el episcopado, al ser fácilmente encuadrables los mencionados.

En cuanto a los Concilios, los representantes castellanos son mejor conocidos, o al menos desde hace más tiempo, especialmente si hablamos de Constanza y Basilea. Sin embargo, también en Siena se puede ver claramente la presencia de una embajada regia ${ }^{193}$. En este sentido se puede apreciar cómo las embajadas regias a los Concilios se estructuran según una forma básica: encabezadas por un prelado (Anaya, Martínez Contreras, Núñez de Isorna), con algún noble presente (Pérez de Ayala en Constanza y Juan de Silva en Basilea ${ }^{194}$ ), y con un secretario regio (Pedro Fernández de Cámara, Enrico Schulte y Juan González de la Maina).

\subsection{Portugal}

Los intentos de Juan I de hacerse con el trono de Portugal, así como la derrota de Aljubarrota seguían teniendo notable peso en las relaciones con el reino vecino a principios del periodo en estudio. Eso influyó notablemente en el envío de embajadas, bien para acordar treguas, bien para conseguir la paz. Y eso se reflejó también en la presencia de eclesiásticos. Esto también tuvo una notable relevancia en la composición de los eclesiásticos que participaron en ellas.

A lo largo del periodo bajomedieval, y dentro de las labores diplomáticas que analizamos, parece lógico pensar que los eclesiásticos hubiesen participado también en la negociación de la paz. Efectivamente, vistas las misiones encomendadas, así fue. Sin embargo, si atendemos a la personalidad de los que participaron, se puede comprobar que existe un cierto desequilibrio en cuanto a la composición, predominando los prelados. Como analicé recientemente, en el caso de la negociación de la paz los prelados

\footnotetext{
${ }^{192}$ Véase al respecto: J. DíAZ IBÁÑEZ, La incorporación de la nobleza al alto clero en el reino de Castilla durante la Baja Edad Media, "Anuario de Estudios Medievales", $35 / 2$ (2005), pp. 557-603.

${ }^{193}$ O. Villarroel GonZÁlez, Castilla y el Concilio de Siena, pp. 134-143.

${ }^{194}$ Rompe la tónica, pues Siena, en el que no aparece ningún miembro de la nobleza castellana. El papel será desempeñado por la cabeza de la delegación aragonesa, Guillermo
Armengol.
} 
tuvieron un notable peso por diversas razones ${ }^{195}$, y durante este periodo esto es perfectamente comprobable. En concreto, en el caso portugués, la situación de enfrentamiento político influyó, sin duda, en cómo se componían esas misiones diplomáticas.

Por ello nos encontramos con las misiones de cinco obispos distintos entre 1392 y 1407 de forma continuada (Juan Serrano (dos veces), Sancho de Rojas, Pedro Fernández de Frías y Juan de Illescas), con un nuevo prelado en 1414 (Juan Rodríguez de Villalón). Pese a ello, no deja de ser curioso que no fuese un prelado el que negociase la paz definitiva, sino que fueron las sucesivas misiones de diversos prebendados (con Alfonso de Cartagena a la cabeza) los que conseguirían el acuerdo. También es el mejor ejemplo de cómo un asunto concreto podía ser encomendado a un personaje hasta su resolución, caso de Alfonso de Cartagena que participó de forma continua, durante los años veinte del siglo, en las misiones diplomáticas a Portugal, hasta que se consiguió la paz. Su conocimiento del reino vecino era tal, o al menos así se consideraba, que cuando haya un roce en el Concilio de Basilea por la cuestión canaria con Portugal se acudirá a él para elaborar la defensa de la posición castellana ${ }^{196}$.

Desde ese momento las misiones se reducen, y desaparecen los prelados de ellas de forma definitiva. Sólo prebendados más o menos cercanos al rey participarían en esas embajadas. ¿Influyó en ello las relaciones pacíficas? Tal vez, pero no deja de ser digno de mención el que así sea. El mejor ejemplo lo encontramos en la negociación con vistas a un nuevo matrimonio del rey, encargada, entre otros, al capellán mayor regio Fernando López de Villaescusa.

\subsection{Aragón}

El reino de Aragón es el segundo principal destinatario de los eclesiásticos embajadores castellanos. En esto, evidentemente, influyeron las muy estrechas relaciones que hubo entre ambos reinos por diversas razones. En un primer momento, durante la minoría de Juan II de Castilla, para conseguir el trono de ese reino para el infante Fernando (lo que supuso una amplia movilización de obispos por parte del poder regio castellano, tanto el representado por el infante como el de la reina Catalina). Como vemos, hubo una gran participación episcopal (Sancho de Rojas, Alfonso de Argüello o Álvaro de Isorna). Motivos más amplios tal vez al caso anterior, pues habría que añadir el hecho de que la participación de prelados podía dar un mayor empaque simbólico a la hora de convencer a aquellos que debían tomar la decisión. Además, tampoco parece baladí el hecho de que para ello se contase

\footnotetext{
${ }^{195}$ Véase al respecto: O. VILLARROEL GONZÁLEZ, Los eclesiásticos en la negociación de la paz, "Guerra y paz en la Edad Media" (A. Arranz Guzmán, M.P. Rábade Obradó y O. Villarroel González, coords.), Sílex, 2011 (en prensa).

${ }^{196}$ Sobre este conflicto véase: L. FERNÁnDEZ GALLARDO, Alonso de Cartagena. Iglesia, política y cultura en la Castilla del siglo XV, Madrid, 1998, pp. 924-1004.
} 
con los principales colaboradores del infante. Parece lógico, dado que era el principal beneficiario de unas buenas relaciones con el reino vecino.

El ascenso al poder de la dinastía Trastámara también en Aragón no supuso la pacificación de las relaciones entre ambos reinos. Muy al contrario, los roces e incluso la guerra, como se sabe, se impusieron. Eso hizo que la diplomacia, y con ella la participación eclesiástica, pasase a primera fila. De esta forma, durante el reinado efectivo de Juan II fueron muchos los embajadores castellanos que acudieron ante Alfonso $\mathrm{V}$ por cuestiones que afectaban a sus hermanos los infantes de Aragón y sus actividades en Castilla. Sin duda el hecho de que se llegase a la guerra abierta también influyó, y con ello, nuevamente, las misiones encabezadas por prelados. La encabezada por Juan Martínez Contreras es, tal vez, la más relevante, por cuanto es aquella de la que se nos conservan más fuentes ${ }^{197}$, aunque muy poco utilizadas en la historiografía castellana ${ }^{198}$.

Una pacificación que fue más aparente que real, puesto que la política interior castellana afectó también posteriormente a las relaciones mutuas. Cuando los infantes de Aragón nuevamente actúen en Castilla, otra vez las embajadas se cruzarán entre ambas cortes, y, evidentemente, participando eclesiásticos. Así ocurrió en 1444, cuando se envió a Juan Alfonso de Cuenca, para conseguir que la paz firmada se respetase pese a los intereses familiares de Alfonso $\mathrm{V}^{199}$. Más si cabe cuando fue nuevamente enviado al año siguiente, en 1445, teniendo en cuenta la tensa situación con Aragón tras la Primera Batalla de Olmedo, donde sus hermanos fueron definitivamente expulsados de Castilla y Enrique muerto a resultas de las heridas.

La situación en las relaciones entre ambos reinos durante el reinado de Juan II desde ese momento se caracterizó más por la paz tensa que por una relación cordial. Es digno de reseña el hecho de que en la embajada de 1445 el rey aragonés no dejase a Juan Alfonso de Cuenca, abad de Alcalá la Real y enviado castellano, siquiera leer las cartas regias que portaba ${ }^{200}$. La expulsión de los infantes de Aragón sin duda no facilitó las cosas. Situación que sería heredada por Enrique IV, siendo digno de reseña el hecho de que este monarca no enviase a ningún eclesiástico a Aragón como embajador.

\subsection{Navarra}

El reino navarro vive una situación extraña en cuanto a sus relaciones diplomáticas con Castilla a lo largo del siglo XV. Si bien apenas recibe atención hasta la tercera década del siglo, desde ese momento, y merced a los

\footnotetext{
${ }^{197}$ CODOIN ACA, XXXVII.

${ }^{198}$ En general es muy poco mencionada y utilizada, muchas veces incluso desconocida. En la actualidad preparo un trabajo sobre esas negociaciones.

${ }^{199}$ BibRAH, colección Salazar y Castro, 9/706, ff. 45 r-40 r; 181 r-207 r y 210 v-211 r.; documentos publicados por I. PASTOR BODMER, Grandeza, II, pp. 55-57, $62-68$ y 52-53, respectivamente.

${ }^{200}$ BibRAH, colección Salazar y Castro, K 81, ff. 80-81; publicado en: I. PASTOR BODMER, Grandeza, II, pp. 104-108.
} 
problemas políticos internos del reino castellano, será objeto de embajadas ante el deterioro de las relaciones mutuas, que llevaron, incluso, a la guerra. El motivo era el hecho de que el infante Juan de Aragón fuese, por su matrimonio con la reina Blanca, también rey de Navarra. Eso hizo que cuando el infante se vio expulsado de Castilla y se llegó incluso a la guerra con Aragón, el reino navarro también participó, y las embajadas remitidas a Aragón formalmente también se dirigían al rey de Navarra, y viceversa, las embajadas aragonesas solían contar también con navarros. Por ejemplo, durante las negociaciones de Ágreda-Tarazona también había representantes navarros ${ }^{201}$. Sin embargo, prácticamente ninguna de las misiones castellanas tuvo como destino el territorio navarro, puesto que el rey no solía residir allí, sino en Aragón.

Buen ejemplo lo encontramos en la embajada de fray Francisco de Soria y de Pedro de Bocanegra ${ }^{202}$, destinados ante los reyes de Aragón y Navarra, pero que en ningún momento pisaron suelo de este último reino, o posteriormente Gutierre de Toledo y Sancho de Rojas ${ }^{203}$.

No sería hasta el reinado de Enrique IV cuando encontremos embajadas compuestas por eclesiásticos y dirigidas ex profeso a Navarra o por cuestiones que afectasen a Navarra directamente. Sería la embajada de Pedro González de Mendoza en $1462^{204}$. Dos años antes se había desarrollado la embajada de Alfonso de Palenzuela que, aunque dirigida al rey Juan de Aragón y Navarra afectó directamente a la política navarra, por cuanto fue un claro acercamiento al príncipe de Viana ${ }^{205}$. Y por último la embajada de Diego Enríquez del Castillo, capellán regio, que acudió ante el príncipe de Navarra y conde de Foix para evitar el enfrentamiento entre ambos reinos ${ }^{206}$.

\subsection{El Imperio y otros ámbitos}

Las relaciones diplomáticas con otros ámbitos distintos de los hasta ahora enunciados fue siempre muy escasa. Qué duda cabe que la lejanía de algunos de ellos, así como las nulas o escasas relaciones que pudiesen llegar a tener influía notablemente en esa falta de contacto diplomático. Y con pocas misiones, obviamente, encontramos pocos eclesiásticos.

De estos otros ámbitos sin lugar a dudas el Imperio ocupa un lugar principal. En primer lugar no era tan alejado, y en segundo lugar sí hubo algún negocio en común que les llevó, en algunos momentos, al contacto

\footnotetext{
${ }^{201}$ En concreto Pedro de Perạlta, Ramiro de Goñi (deán de Tudela) y Pascual de Oteyza (arcediano de Barbadiego y licenciado en decretos), CODOINCA, XXXVII, p. 18.

${ }^{202}$ L. GALÍNDEZ DE CARVAJAL, Crónica del serenísimo príncipe, p. 452 , vid. supra, las relaciones con Aragón.

${ }^{203}$ Ibídem, pp. 463 y 471, respectivamente.

${ }^{204}$ D. ENRÍQUeZ DEL CASTILlO, Crónica, cap. LIII, p. 207.

${ }^{205}$ D. ENRÍ́OUEZ DEL CASTILlo, Crónica de Enrique IV, ed. A. Sánchez Martín, Valladolid, 1994, cap. XXVI, p. 172.

${ }^{206}$ Ibídem, cap. LXXXIII, p. 252.
} 
directo. El Cisma y los problemas del Concilio de Basilea serían los puntos de encuentro de ambos soberanos. Es decir, cuestiones puramente eclesiásticas que hicieron, sin duda, que la presencia de clérigos fuese más nutrida. Ciertamente no eran los únicos, puesto que están documentados algunos roces comerciales, pero que no llevaron a la actuación político-diplomática ${ }^{207}$.

Ya con Enrique III encontramos los primeros enviados: Fernando de Illescas y el obispo zamorano Juan García Fernández ${ }^{208}$. El mismo motivo (la preocupación por la situación de la Iglesia) llevaría al contacto años después, tal sería el caso de las misiones de Alfonso de Cartagena y Rodrigo Sánchez de Arévalo, enmarcadas en el conflicto entre el Concilio de Basilea y el papa Eugenio IV, en el que mediaron los poderes políticos ${ }^{209}$, que sería seguida por una segunda embajada en 1442, cuando Castilla ya no reconocía el Concilio pero se seguía trabajando para su conclusión definitiva, haciendo que volviese a aceptar a Eugenio IV ${ }^{210}$.

Las dos últimas embajadas regias a comentar tienen una relevancia distinta. Una por dirigirse a un ámbito de poder menor y no soberano, como eran los condes de Armagnac, a quien se envió a un monje llamado Remón en 1431 (con el claro objetivo de tener un aliado al otro lado del Pirineo que pudiese increpar las posesiones ultrapirenáicas del rey navarro) ${ }^{211}$.

Y por último cabe mencionar la embajada a Tamerlán. Es, posiblemente, la más curiosa o al menos la que más curiosidad ha despertado, de entre las misiones diplomáticas castellanas de Enrique III. Como se sabe, en 1401 envió una primera embajada de paz y amistad a oriente, tanto al sultán Bayaceto como a Timur Lenk. Esta primera misión, atendida por el emperador mogol tras su victoria en Ankara, sería el origen de la segunda, que partió en 1403, en la que sí participó un eclesiástico, Alfonso Páez de Santamaría, fraile dominico y maestro en Teología ${ }^{212}$. No ha de extrañar la presencia de un eclesiástico en esta misión, más teniendo en cuenta sus estudios y su pertenencia a la orden de predicadores.

\section{FORMACIÓN Y EXTRACCIÓN: ANÁLISIS CUANTITATIVO}

A lo largo de los tres reinados en estudio la presencia de eclesiásticos en las embajadas fue muy amplia. Pero, ¿qué tipo de formación tenían esos

\footnotetext{
${ }^{207}$ A. LÓPEZ FerreIro, Historia de la SAMI de Santiago de Compostela, VII, Santiago de Compostela, 1904, p. 153.

${ }^{208}$ A. LÓPEZ, Fray Fernando de Illescas, p. 248.

${ }^{209} \mathrm{Al}$ respecto véase: L. FERNÁNDEZ GALlARDO, Alonso de Cartagena. Una biografía política, pp. 209-223.

${ }^{210}$ V. Beltrán de Heredia, Cartulario, I, p. 384.; L. Serrano, Los conversos, p. 212.

${ }^{211}$ L. GALÍNDEZ DE CARVAJAL, Crónica del serenísimo príncipe, p. 494. Para un análisis de las relaciones con ese condado: C. OLIVERA SERRANO, Los condes de Armagnac. Véase al respecto lo que comenté en: El rey y la iglesia castellana, capítulo segundo, apartado 5.2.5.

${ }^{212}$ R. GONZÁlez DE ClaviJo, Embajada a Tamorlán, ed. F. López Estada, p. 31 de la introducción.
} 
eclesiásticos? ¿Cuál era su posición dentro de la Iglesia? Es hora de analizar tanto el origen, como los estudios, como la posición en la jerarquía eclesiástica de los elegidos por el monarca para servirle como embajadores. Dado que en algún caso hemos podido detectar mayor o menor presencia de prelados (como ya se ha comentado para el caso portugués), cabe analizar la composición general de las embajadas, para poder extraer información sobre por qué se elegía a un embajador en concreto.

En primer lugar podría llamar la atención el hecho de que haya cuarenta cuatro personas de las que desconocemos el grado de formación que tenían. Esto supone casi la mitad de los embajadores muestreados. De todos ellos hay informaciones variadas. No llegamos a conocer qué grado de estudios tenían todos ellos, pero incluso de los que lo desconocemos, en algún caso sí podemos llegar a conocer algún dato, siquiera incompleto, a la hora de analizar descripciones biográficas de época de esos personajes. Así, por ejemplo, de Pablo de Santa María se dice que era "gran letrado en ambas leyes, filósofo y teólogo"213 , y de Sancho de Rojas, arzobispo de Toledo, que era buen letrado ${ }^{214}$. Del mismo modo, de algún otro tenemos noticias que les juzgan bastante más negativamente, así, por ejemplo, de Pedro Fernández de Frías, cardenal, Pérez de Guzmán dice que no era muy letrado ${ }^{215}$.

De los que sí tenemos datos, en ocasiones los tenemos muy abundantes, y alguno de ellos tenía amplios estudios en varias disciplinas. Así, nos encontramos con doce maestros (normalmente en teología), diez bachilleres, seis licenciados, veinticuatro doctores y trece personas de las que sabemos que tenían estudios pero no el grado alcanzado.

\section{Grafico 1. Grado de formación de los embajadores}

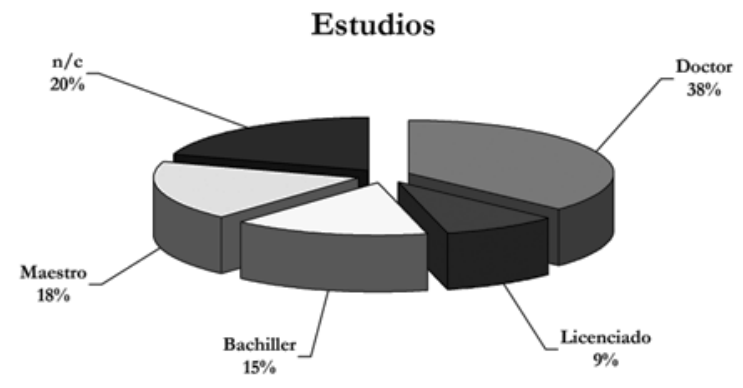

${ }^{213}$ F. PÉREZ DE GuZMÁN, Generaciones y semblanzas, ed. A. Paz y Meliá, en el número 68 de la Biblioteca de Autores Españoles, pp. 697-719, en concreto pp. 709-710.

${ }^{214}$ Ibídem, p. 719.

${ }^{215}$ Ibídem, p. 712. 
En cuanto a las temáticas, veintitrés son especialistas en decretos, catorce en leyes, dieciséis en teología, dos en Artes y de cuarenta y cuatro no sabemos la especialidad. Como vemos, es muy alto el número de personajes sobre los que no hay mención a sus estudios, pero entre los que sí llegamos a conocer hay un alto porcentaje de decretistas. En total, hay un veintitrés por ciento de decretistas, catorce de legistas, dieciséis de teólogos, dos de Artes y un cuarenta y cinco del que no sabemos nada. En algún caso podríamos pensar que los tenían, sobre todo cuando desempeñan puestos en la curia o en la administración regia, pero no se puede asegurar al cien por cien de posibilidades y, menos aún, aventurar el tipo de estudios.

\section{Gráfico 2. La especialidad de los embajadores}

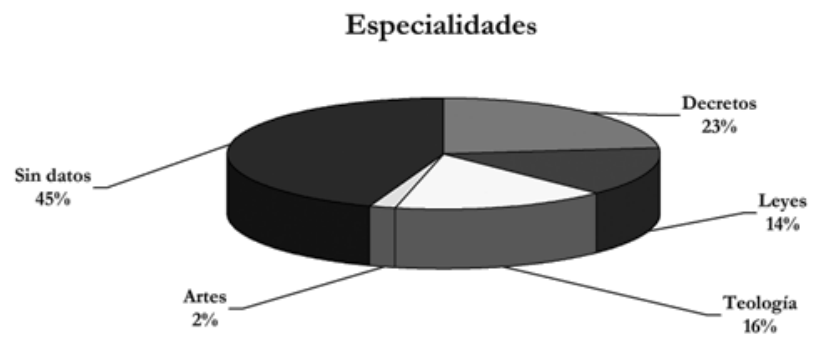

En cuanto al nivel que alcanzaron en la jerarquía eclesiástica, vemos que hay cincuenta y cuatro prelados, cuarenta y nueve prebendados de distinto tipo (deanes, arcedianos o abades seculares), siete abades exentos, seis priores, cinco canónigos y seis frailes (franciscanos y dominicos), dos cardenales y veinticinco clérigos de los que no conocemos ningún cargo de la jerarquía eclesiástica (lo que no significa que no lo tuviese). Se han contabilizado las misiones de forma independiente a los enviados, puesto que hubo muchos que fueron comisionados en varias ocasiones y que fueron ascendiendo en el ínterin. De esta forma se refleja la posición en la jerarquía eclesiástica de los embajadores castellanos en todas las misiones, independientemente de las personas. 


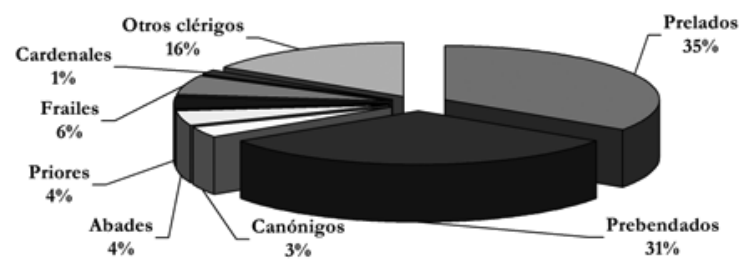

Como vemos, hay una notable diferencia entre los dos primeros grupos, los prelados y los prebendados, y el resto. Ellos fueron el grueso de los enviados eclesiásticos de los reyes de Castilla.

En una visión general podríamos pensar que ambos grupos participan por igual, sin embargo conviene hacer una visión diacrónica. Recientemente analicé cómo durante la mayoría de edad de Juan II predominaron los prebendados sobre los prelados, a la hora de participar en las misiones diplomáticas ${ }^{216}$. Por ello, parece conveniente, sobre todo a la vista del listado de embajadores y de las embajadas, analizar en los distintos reinados la composición jerárquica de las embajadas.

\section{Gráfico 4. El reparto en los diversos periodos}

\section{Los diversos periodos}

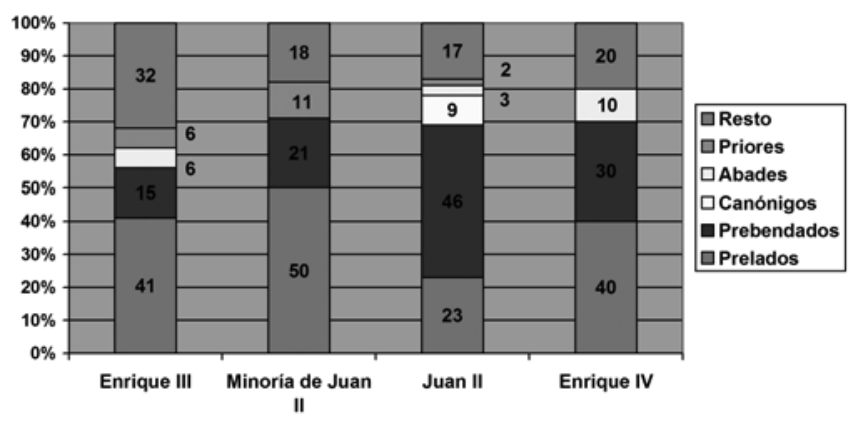

${ }^{216}$ O. VILLARROEL GONZÁLEZ, El rey y la Iglesia castellana, capítulo segundo, apartado 5.3. 
Así, como se puede observar en la gráfica 4, durante el reinado de Enrique III los prelados supusieron el cuarenta y uno por cierto de los embajadores eclesiásticos, mientras que los prebendados fueron sólo el 15. Durante la minoría de Juan II (que aquí separamos por ostentar el poder regio una persona distinta ${ }^{217}$ ) el número de prelados ascendió hasta el cincuenta por cierto, aunque los prebendados aumentaron hasta el veintiuno. El reinado efectivo de Juan II supone el vuelco en la composición de las embajadas. Los prelados se reducen al veintitrés por cierto, ascendiendo los prebendados hasta el cuarenta y seis, a lo que se podía sumar el nueve por ciento de canónigos (el más alto de todo el periodo). Con su hijo Enrique IV la situación, sin que se vuelva a la preponderancia de los prelados de épocas anteriores, sí vemos que se produce un cierto cambio, ascendiendo los prelados al cuarenta por cierto y reduciéndose los prebendados al treinta. Además, este último llama la atención porque desaparecen por completo los abades y priores en la composición de las embajadas.

Con todo ello se nos plantean algunas cuestiones, que nos permiten extraer algunas conclusiones interesantes. ¿Por qué ese aumento de los prebendados? En otro lugar ya he analizado la situación concreta del reinado de Juan $\mathrm{II}^{218}$. La situación política interna del reino tuvo mucho que ver en que se evitase recurrir a prelados, pues normalmente estaban más politizados que los prebendados. De hecho, en muchas ocasiones cuando se recurría a un prelado era con una clara intencionalidad política. Así, por ejemplo, cuando Gutierre Gómez de Toledo es enviado a Aragón, siendo ya obispo de Palencia en $1429^{219}$, o Sancho López de Vesco, obispo de Salamanca, en $1424^{220}$, parece evidente que se trata de mostrar a los infantes de Aragón allí refugiados, y al propio monarca, cómo antiguos partidarios colaboran activamente con el rey, pues ambos lo habían sido ${ }^{221}$. Además, en cinco ocasiones los prelados habían acudido a participar en Concilios (Martínez Contreras, Rojas, Isorna, Cartagena y Santamaría), y uno más fue enviado al papa (Isorna en 1421), misiones en las que su posición eclesiástica sin duda era relevante.

Este tipo de apreciaciones pueden aplicarse al resto de los periodos. Sin lugar a dudas la intensa actividad diplomática en torno al Cisma hizo que Enrique III recurriese frecuentemente a prelados. Además, el hecho de que

\footnotetext{
${ }^{217}$ No entraré aquí a deslindar lo que pertenece al infante Fernando y a la reina Catalina, por ser un periodo que aún ha de ser atendido específicamente y que, posiblemente, merecería un trabajo específico, por la dificultad de diferencia entre un regente y otro. Sobre la minoría véase: O. VILLARROEL GONZÁLEZ, El rey y la Iglesia castellana, capítulo primero; y, sobre todo la tesis doctoral de Santiago González Sánchez, recientemente defendida en la Universidad Complutense de Madrid, La Corona de Castilla: vida política (1406-1420). Acontecimientos, tendencias y estructuras.

${ }^{218}$ O. VILLARROEl GONZÁLEZ, El rey y la Iglesia castellana, capítulo segundo, apartado 5 y 5.3., en concreto, para las conclusiones.

${ }^{219}$ L. GaLÍNDEZ DE CARVAJAL, Crónica del serenísimo príncipe, pp. 387-388.

${ }^{220}$ A. García de SANTAMARÍA, Crónica, pp. 333-334.

${ }^{221}$ Véase al respecto O. VILLARROEL GONZÁLEZ, El rey y la Iglesia castellana..., apéndice prosopográfico.
} 
entre ellos encontrase fieles colaboradores también es algo a tener en cuenta, como serían los casos de Alfonso de Egea, Juan Serrano o Juan de Illescas. Sin lugar a dudas la necesidad de conseguir la pacificación con Portugal también influyó mucho en la presencia de prelados, no en vano todos los embajadores eclesiásticos que remitió eran obispos (Juan Serrano en dos ocasiones, Sancho de Rojas y Pedro Fernández de Frías). Éste último, además, hay que tener en cuenta que llegó a ser considerado como uno de los principales colaboradores regios ${ }^{222}$. De este modo, fueron condicionantes más bien externos los que llevaron a ese gran número de prelados. Habría, no obstante, que comprobar en los periodos anteriores qué relevancia habían tenido en la diplomacia, pues estamos, muy posiblemente, más bien ante la continuidad de una tónica que en una innovación.

La minoría de Juan II se regiría por patrones distintos. La relevancia que algunas cuestiones políticas pudieron llegar a tener sin duda fomentó ese aumento de los prelados tan inusitado. Si atendemos a quiénes fueron la situación parece aclararse. De nuevo la mayor parte de los enviados a Portugal fueron prelados, pero sólo fueron dos (Juan de Illescas y Álvaro Núñez de Isorna). El resto o fueron enviados a Aragón (para conseguir la corona de Aragón para el infante Fernando) o tuvieron misiones relacionadas con el fin del Cisma (bien al emperador, bien a las vistas de Perpiñán, bien a Benedicto XIII). Es decir, políticas claramente dirigidas por el infante Fernando ${ }^{223}$. Y los participantes en ellas nos indican bien claramente por qué fueron elegidos: Sancho de Rojas, que se decía a sí mismo "fechura" del infante ${ }^{224}$, Isorna, que había sido maestro del infante y fue su primer delegado en Aragón ya en 1411 y que estaba en su consejo ${ }^{225}$, Diego Gómez de Fuensalida, su primer embajador en Aragón, ya en $1410^{226}$, o Alfonso de Argüello, que defendió su precedencia ante Juan II al trono de Aragón y con quien colaboró en sus nuevos reinos ${ }^{227}$. Es decir, personajes claramente afines al infante Fernando y fieles a su persona.

Y esa situación política de la minoría regia afectó, sin duda, al reinado personal de Juan II, y con ello a la elección de sus embajadores eclesiásticos. El hecho de que el episcopado estuviese, al menos en sus principales figuras, claramente marcado por la política de Fernando de Antequera, y claramente

\footnotetext{
${ }^{222}$ F. PÉREZ DE GUZMÁN, Generaciones, p. 719.

${ }^{223}$ El peso del infante en la dirección de la política castellana: L. Suárez Fernández, Castilla, p. 66 y ss.; O. Villarroel González, El rey y la Iglesia castellana, capítulo primero, apartado 1.4 En él analizo la personalidad de los enviados y los representantes castellanos.

${ }^{224}$ Archivo de la Corona de Aragón, Cancillería, Cartas Reales, Fernando I, caja 18, n. ${ }^{\circ} 2210$ y caja $27 \mathrm{n} .^{\circ} 3445$.

${ }^{225}$ J. GoÑ GAZTAMBIDE, Los españoles en el Concilio de Constanza, II, p. 151; L. GALínDEZ DE CARVAJAL, Crónica del serenísimo príncipe, pp. 337 y 339; è ibídem, p. 347, respectivamente.

${ }^{226}$ J. ZURITA, Anales de la Corona de Aragón, ed. electrónica de la Institución Fernando el Católico, vol V, libro XI, p. 30.

${ }^{227}$ Llegó a ser canciller mayor del rey de Aragón (AC Sigüenza, $\mathrm{n}^{0} 353$ del catálogo de Hilario Yaben, hoy desaparecido) y arzobispo de Zaragoza (K. Eubel, Hierarchia Catholica medii aevi, Munster, 1913, I, p. 153.
} 
encuadrado en las filas de los que apoyaban a sus hijos los infantes de Aragón, hizo que el monarca buscase en personajes de menor rango el apoyo que necesitaba. Recurrirá a los prelados, como hemos visto, pero incluso en ese caso se hace una clara utilización política e incluso propagandística de su participación. Los prebendados, sin embargo, le aportaban gente formada y sin lazos familiares que les atasen a la alta nobleza (al menos en muchos casos), dispuestos a colaborar con él (y que serían recompensados, obviamente).

Durante el reinado de Enrique IV la relevancia de los prelados en las embajadas se ve desproporcionada por la presencia de Alfonso de Palenzuela. Sin lugar a dudas fue el principal colaborador regio en este sentido, llevando a cabo cinco misiones diplomáticas por encargo de Enrique IV, con lo que él sólo desequilibra la correlación con los prebendados puesto que supone un tercio del total. Si a eso añadimos la presencia de Pedro González de Mendoza, uno de los principales colaboradores eclesiásticos y políticos de Enrique IV, hace que la relevancia de los prelados quede clara en su intencionalidad: la participación de los más cercanos colaboradores regios. En este caso de nuevo el rey de Castilla pudo contar entre el episcopado con alguno de sus más fieles sirvientes, a diferencia de lo que le había ocurrido a su padre. Aún así, vemos cómo el número de prebendados es superior al de la minoría de Juan II, o al del reinado de Enrique III, con lo cual realmente podemos ver cómo sigue la línea ascendente en cuanto al servicio diplomático de este tipo de personajes tras el excepcional paréntesis de Juan II.

\section{CONCLUSIONES}

En general, a la vista de los datos cuantitativos se puede indicar cómo a lo largo del periodo en estudio la monarquía castellana tendió a utilizar eclesiásticos de la parte media y alta de la jerarquía eclesiástica, aunque paulatinamente los prelados iban perdiendo importancia. Lo más normal es que fuese un prebendado, doctor o bachiller, y con más posibilidades de serlo en decretos que en leyes. También es digno de tener en cuenta el hecho de que entre ellos hubo algunos que desempeñaron importantes labores de colaboración con el monarca en su incipiente administración. Así, entre ellos hubo siete confesores regios, nueve capellanes (incluido Fernando López de Villaescusa, capellán mayor de Enrique IV ${ }^{228}$ ), dos oidores de la Audiencia Real (Álvaro Núñez de Isorna y Sancho de Rojas), dos consejeros reales y nueve secretarios reales. Sin lugar a dudas éste último dato es relevante, especialmente la participación constante de un miembro de éste grupo en las misiones enviadas a los Concilios.

Otro de los datos que salta a la vista si comparamos las embajadas con la biografía de cada uno de los personajes es que la colaboración en este tipo

${ }^{228}$ D. EnRíQueZ DEl CASTILlo, Crónica, cap. XIV, p. 155. 
de tareas (para aquellos que servían al rey más de una vez) solía serles beneficioso, puesto que acababan entrando en el episcopado. Esto tiene lógica si tenemos en cuenta que los reyes optaban por conseguir entregar sedes episcopales a aquellos eclesiásticos que le demostraban su fidelidad y valía. Así, Alfonso de Argüello comenzó a servir a la casa regia castellana como un monje franciscano en $1397^{229}$, y en 1403 ya había recibido la sede leonesa ${ }^{230}$. Sancho de Rojas era abad de Salas cuando estuvo en Siena ${ }^{231}$, y obispo de Astorga cuando fue enviado a Aragón e Inglaterra ${ }^{232}$. Gutierre de Toledo era arcediano de Guadalajara al partir hacia la Curia, y obispo de Palencia en el momento de sus embajadas a Aragón ${ }^{233}$. Juan Rodríguez de Villalón era prior de Husillos en su primera misión en $1409^{234}$, arcediano de Grado en su primera misión en Portugal en $1411^{235}$, pero ya era obispo de Badajoz cuando marchó como embajador ante Benedicto XIII años después ${ }^{236}$. O Alfonso de Cartagena, que era deán de Santiago al acudir a Portugal ${ }^{237}$, y cuando marchó a Alemania ya era obispo de Burgos ${ }^{238}$.

Obviamente eso no quiere decir que el servicio diplomático al rey supusiese una forma segura de promoción eclesiástica. De hecho, muchos de los embajadores no repitieron su misión y su ascenso en la jerarquía eclesiástica fue nulo o muy limitado. Por ejemplo, Pedro de Bocanegra sirvió como embajador a Juan II entre 1429 y 1436 en tres misiones distintas, pero siempre como deán de Cuenca ${ }^{239}$, o Fortún Velázquez de Cuéllar, que tras servir en la Curia en 1443 a Juan II $^{240}$, y posteriormente a Enrique IV en Francia en $1454^{241}$ y ante el papa en $1460^{242}$, no sería hasta después de esta última misión que alcanzase la sede episcopal de León ${ }^{243}$.

De hecho, durante mucho tiempo el prebendado que seguía siendo prebendado podía considerarse como embajador modelo, y ellos serán los que más veces repitan embajada. Así, Juan Alfonso de Mella fue embajador en

\footnotetext{
${ }^{229}$ A. LóPeZ, Fray Fernando, p. 248.

${ }^{230} \mathrm{ASV}$, Reg. Avin., 307, f. 61.

${ }^{231} \mathrm{AC}$ de Burgos, Volúmenes, 19, f. 124.

${ }^{232}$ L. GALÍNDEZ DE CARVAJAL, Crónica del serenísimo príncipe, pp. 471 y 482.

${ }^{233}$ L. GALÍNDEZ DE CARVAJAL, Crónica del serenísimo príncipe, pp. 387-388.

${ }^{234}$ ASV, Reg. Vat., 332, ff. 4 v-5 r.

${ }^{235}$ M.F. DE BARRos SousA, Quadro, p. 286.

${ }^{236}$ AGS, Patronato Real, leg. $21, \mathrm{n}^{\circ} 9$.

${ }^{237}$ AGS, Patronato Real, leg. 49, ff. 16-17; L. Galíndez de CARvajal, Crónica del serenísimo príncipe, p. 411.

${ }^{238}$ Recibió la sede en 1435 y fue nombrado embajador en 1437: L. SERRANO, Los conversos, pp. 106 y 150.

${ }^{239}$ Para 1429: L. GALÍNDEZ DE CARVAJAL, Crónica del serenísimo príncipe, p. 452; para 1436: AGS, Estado-Francia, K.1711, ff. 440-442. Aunque rechazó en 1429 la sede tudense (V. BELTRÁN DE HEREDIA, Cartulario, I, p. 358.

${ }^{240}$ ASV, Reg. Vat., 367, f. 165r.

${ }^{241}$ A. PAlenCia, Gesta, I, p. 101.

${ }^{242}$ PIO II, Commentarii rerum memorabilium, II, p. 282. Se refiere a él como "Legionemsem

${ }^{243}$ K. EuBEL, Hierarchia, II, p. 174. Murió en junio de ese mismo año.
} episcopus". 
dos ocasiones, en $1423^{244}$ y en $1433^{245}$, siempre antes de alcanzar la sede episcopal de Zamora. Gil Fernández de Toledo fue embajador en la Curia durante al menos cuatro años, siempre siendo $a^{2} a^{246}$. Pedro de Bocanegra lo fue en dos ocasiones entre $1429^{247}$ y $1436^{248}$, siempre como deán de Cuenca. Alfonso González de Herrera fue embajador en la Curia durante al menos cuatro años, y siempre como abad de Santa Colomba (prebenda de la diócesis de Sigüenza) ${ }^{249}$. O Pedro Fernández de Cámara, que entre 1415 y 1422 fue embajador ante el papa ${ }^{250}$, en el Concilio de Constanza ${ }^{251}$, y después de nuevo ante el papa, siempre como arcediano de Grado ${ }^{252}$.

En ocasiones ya eran prelados, pero eso les servía para seguir progresando en sus carreras. Por ejemplo, Alfonso de Egea acudió a Francia como obispo de Zamora en $1391^{253}$, en 1403 ya lo era de Ávila y ese mismo año fue trasladado al arzobispado de Sevilla ${ }^{254}$. O Sancho de Rojas, que en 1411 era obispo de Palencia ${ }^{255}$, y tras sus servicios a Fernando de Antequera fue elevado a la sede arzobispal toledana ${ }^{256}$.

Otra de las características que podemos apreciar, y que ya nos venía sugerida por la gran cantidad de eclesiásticos que participaron en las actividades diplomáticas, es la escasez de personajes que hiciesen una auténtica carrera en este servicio al rey. La mayor parte de ellos lo hicieron una sola vez, solo unos pocos repitieron, y menos todavía lo hicieron más de tres veces. En concreto cincuenta realizaron una única misión, veinte sólo dos, diez llegaron a realizar tres, nada más que cinco lo hicieron cuatro veces, dos durante cinco ocasiones (Álvaro de Isorna y Alfonso de Palenzuela) y sólo uno llevó a cabo seis misiones (Pedro Fernández de Cámara). Éste fue, sin lugar a dudas, el que más larga trayectoria diplomática mostró pues, iniciando sus labores con Enrique III, siguió desarrollándolas durante la minoría, y las finalizaría ya en época del reinado personal de Juan II.

Mención aparte, eso sí, merecerían aquéllos que desarrollaron misiones fijas durante varios años: Alfonso González de Herrera y Gil

${ }^{244} \mathrm{ASV}$, Reg. Vat., 354, ff. 167v-168r; publicado en L. SUÁREZ FERNÁNDEZ, Castilla, pp. 319-320; y en V. BELTRÁN DE HEREDIA, Bulario, II, doc. 660, p. 223.

${ }^{245} \mathrm{~V}$. BELTRÁN DE HEREDIA, Bulario, II, doc. 855, p. 374.

${ }^{246}$ ASV, Reg. Vat., 359 f. 85; transcrito por T. Minguella y ARNEDO, Historia de la diócesis, II, p. 109, y doc 154, pp. 635 y ss.

${ }^{247}$ L. GALÍNDEZ DE CARVAJAL, Crónica del serenísimo príncipe, p. 452.

${ }^{248}$ V. BELTRÁn DE HEREDIA, Cartulario, I, p. 360, citando: AGS, Estado-Francia, K-1711, ff. 440-442. V.A. ALVAREZ PALENZUELA, La situación europea, p. 319.

${ }^{249}$ Archivo de la Casa Ducal de Alba, leg. 222-5, sin número de documento; publicado por J.M. Nieto Soria, Dinero y política, pp. 1067-1969.

${ }^{250}$ L. Serrano, Los conversos don Pablo de Santa María, p. 65.

${ }^{251}$ AGS, Patronato Real, leg. 21, $\mathrm{n}^{\circ} 9$.

${ }^{252}$ V. BELTRÁN DE HEREDIA, Bulario, II, doc. 653, pp. 216-217.

${ }^{253} \mathrm{G}$. DAUMET, Étude sur l'alliance de la France, p. 60.

${ }^{254}$ ASV, Reg. Avin., 331, f. 624.

${ }^{255}$ L. GALÍNDEZ DE CARVAJAL, Crónica del serenísimo príncipe, p. 336.

${ }^{256} \mathrm{ASV}$, Reg. Avin., 346, ff. 286r. 
Fernández de Toledo en la Curia, los que acudieron a los Concilios..., además de los laicos que hicieron otro tanto, como Luis Álvarez de Paz ${ }^{257}$. De este modo, lo más normal es pensar que después de sus servicios diplomáticos pasasen a colaborar con el rey de otra manera, pero esto ocurrió en pocos casos, la mayor parte de ellos sirvieron al monarca sólo en este tipo de tareas. Indudablemente hay que exceptuar a algunos, y es digno de mención el hecho de que sean los más activos. ¿Acaso el rey hacía un constante ejercicio de selección de personal? Tal vez parezca exagerado, pero podría ser acertado. Sobre todo cuando aquéllos que vemos repetirse en embajadas pasaron después a la Audiencia o al Consejo.

En definitiva, podemos concluir que en la diplomacia el monarca castellano casi siempre se decidió por personas procedentes de familias de orden menor en cuanto a su importancia política (solo estarían las excepciones de Gutierre Gómez de Toledo y Alfonso de Velasco), con una formación en leyes, normalmente sólida, y que no desempeñaban importantes puestos ni en la corte ni en la jerarquía eclesiástica. En las embajadas solían rodearse de un séquito de cierta importancia, fuese un solo embajador o varios. Sería extraño que los embajadores repitiesen su actividad, siendo más común el que pasasen a desempeñar otro tipo de labor al servicio regio, además de que en ocasiones los elegidos ya habían desempeñado otras con anterioridad. No parece que existiese una profesionalización de las labores diplomáticas, si bien la especialización de algunos de los personajes (sobre todo Fernández de Cámara o Alfonso de Cartagena) nos indica claramente personajes muy formados y capaces que atrajeron en ese sentido la atención del monarca, que no dudó en utilizar sus servicios.

Fecha de recepción del artículo: abril de 2010.

Fecha de aceptación y versión final: julio de 2010. pássim.

${ }^{257}$ Sobre la actuación de estos personajes: O. VILLARROEL GONZÁLEZ, El rey y el papa..., 